\title{
Induced Currents in Pipelines
}

\author{
Virginia Mabel Silbergleit \\ CONICET, Instituto del Gas y del Petroleo, Facultad Ingenierıa, Universidad de Buenos Aires, Buenos Aires, \\ Argentina \\ Email: vms10ar@yahoo.com.ar
}

Received 4 March 2015; accepted 30 April 2015; published 6 May 2015

Copyright @ 2015 by author and Scientific Research Publishing Inc.

This work is licensed under the Creative Commons Attribution International License (CC BY).

http://creativecommons.org/licenses/by/4.0/

\section{(c) (i) Open Access}

\begin{abstract}
Changes in the geomagnetic field produce ground induced currents that can have impacts on artificial systems such as pipelines. According to these, geomagnetic perturbations observed during June 2005 are studied. The data measured on the Ottawa River Valley pipeline verify the appearance of induced currents greater than $700 \mathrm{~mA}$ and additional potential values larger than $-850 \mathrm{~V}$ that can produce additional corrosive effects.
\end{abstract}

\section{Keywords}

Storm, Induced Currents, Pipelines

\section{Introduction}

Geomagnetic disturbances can impact the operational reliability of buried pipelines. Storm events provide compelling evidence of a general increase of corrosion in pipeline systems.

The cathodic protection (CP) is to prevent corrosion by maintaining buried pipelines at a constant potential with respect to the soil. Design requires characterization of the parameters impacting the corrosion process. A non corrosive coating is used to prevent damage, and additional protection is applied by means of CP in order to control galvanic current.

The voltage (PV) at test places must be in the safe range, which is within the -850 to $-1150 \mathrm{mV}$ which is affected by CP system. The PV readings are irregular and at times full outside the safe zone. They are influenced by the geomagnetic activity, the Earth conductivity and the pipeline structure [1]. Many authors studied the induced currents (PI), e.g. [2]-[4].

The corrosion could lead to a major ecological tragedy of oil poured out of a hole in a pipe line in the deserts of Alaska. They are, therefore, closely monitored and protected. To avoid the leakage of iron electrons into the ground, pipelines have a coating of low conduction material and are maintained artificially at a slightly negative potential in relation to the Earth $(-0.85 \mathrm{~V})$, to prevent migration of electrons. However, corrosion is increased by 
the electric currents that spread though the ground during magnetic storms and substorms. High latitudes are particularly exposed to accelerated corrosion

The electric and magnetic fields observed at the Earth's surface depend on magnetospheric-ionospheric currents and on currents induced in the Earth. Recent developments in the use of the Complex Image Method (CIM) permit fast and accurate computations of the electric field suitable for time-critical applications like GIC (geomagnetically induced currents) forecasting. The physical background and modeling of induced currents are discussed in his paper [5].

Telluric currents produced by geomagnetic disturbances during magnetic storms and substorms can cause variations in the difference in potential with the ground; they modify the electrochemical conditions of the pipe leaving which can be temporarily not protected [6]-[8].

Telluric current effects have had a significant effect on electrical systems for over 150 years [9] and on pipelines firstly observed in 1950. We examined the electromagnetic response of a buried pipeline in soil (placed in the Otawa River Valley) during a perturbed periods.

\section{The DSTL Approach}

Geomagnetic field variations induce telluric currents in pipelines, which change the electrochemical conditions at the pipe/soil interface, probably contributing to corrosion of the pipeline steel. Pipe to soil potentials produced by the electric field induced in the pipe were considered by using a distributed source transmission line (DSTL) model. This was used and applied to geomagnetic induction in pipelines by different authors [3] [7]. In the DSTL approach each uniform section of the pipeline is represented by a circuit with specific series impedance and a parallel admittance (as it is shown in Figure 1).

$$
\begin{aligned}
\partial \mathrm{E}^{\prime} / \partial x & =\left[\partial^{2}(\mathrm{PV}) / \partial^{2} x-\alpha^{2}(\mathrm{PV})\right] \\
-\mathrm{A}^{\prime} \mathrm{E}^{\prime} & =\left[\partial^{2}(\mathrm{PI}) / \partial^{2} x-\alpha^{2}(\mathrm{PI})\right]
\end{aligned}
$$

where $\alpha \sqrt{\mathrm{I}^{\prime}} \sqrt{\mathrm{A}^{\prime}}$ is the propagation constant along the pipeline, $\mathrm{A}^{\prime}$ is the parallel admittance and $\mathrm{I}^{\prime}$ is series impedance per unit length. The induced electric field is represented by voltage sources distributed along the transmission line (Figure 1).

Equations (1) and (2) are the basic equations for the voltage (PV) and current (PI) produced in any section of pipeline by induced electric field E'.

In the DSTL model, the pipeline is considered as a transmission line, with multiple segments of different lengths and orientations. The induced electric field is represented by voltage sources distributed along the transmission line. The electric properties of the pipeline are the series impedances per unit length and parallel admittance per unit length. Also, the conductance is through the pipeline coating. The potential difference between a pipeline and the adjacent Earth influences the electromechanical environment at the pipe surface, which modify possible corrosion occurrence. According to this, anodes and rectifier units are connected to the pipeline steel to drive it negative with respect to the surrounding soil. In this case, the pipe becomes the cathode of the circuit, leading to the name "cathodic protection" [10].

Recordings of the geomagnetic variations in the region of the pipeline can be obtained from permanent magnetic observatories or specially installed magnetometers. [11] studied characteristic of geomagnetic storms.

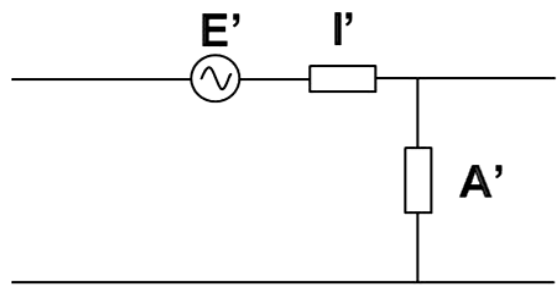

Figure 1. In the DSTL model, each uniform section of the pipe is represented by a circuit element with specific series impedance ( $\left.\mathrm{I}^{\prime}\right)$ and a parallel admittance (A'). The induced electric field is represented by voltage sources distributed along the transmission line. 


\section{Additional Corrosion in Pipelines}

To prevent the migration of iron electrons into the ground, pipelines have a coating of low conduction material and are maintained at a slightly negative potential in relation to the Earth of the $-0.85 \mathrm{~V}$. However, corrosion could be increased by the electric currents that spread through the ground during magnetic perturbations. The above mentioned pipeline features cause the pipeline system to respond to the geomagnetic variations in a more complicated way.

The geomagnetic Dst index, as published by World Data Center C2 and developed by [12] is considered. The temporal evolution of this index during the perturbed period is shown in Figure 2. The disturbed period analyzed in this article shows a Dst minimum value of $-106 \mathrm{nT}$. Geomagnetic field recordings from the Ottawa Magnetic Observatory are used to calculate the electric field at the Earth's surface [6]. A simple layered conductivity model of the Earth is considered.

The results developed by [8], show an important similarity in the electric field E and the pipe to soil potential values $\mathrm{PV}$.

The following pipeline values are considered: outer diameter $762 \mathrm{~mm}$, thickness $9.8 \mathrm{~mm}$, resistivity of the steel $0.1786 \times 10^{-6} \mathrm{ohm}-\mathrm{m}$, then the resistance of a pipeline $80 \mathrm{~km}$ length is $1785.7 \mathrm{ohms}$ [1] [13]. Then, the PV values are calculated by

$$
(\mathrm{PV})(\mathrm{mV})=\mathrm{A}+\mathrm{B} \mathrm{E}_{y}=\left[(-980 \pm 80)+(11 \pm 2) \mathrm{E}_{y}\right]
$$

where $E_{y}$ is the y-component of the electric field $E\left(E_{x}, E_{y}\right)$.

According to Equation (3), the coefficients are:

$\mathrm{A}=(-982 \pm 80) \mathrm{mV}$ give the pipe to soil potential offset (effect of the cathodic protection) and

$\mathrm{B}=(11 \pm 2) \mathrm{km}$ give the ratio of the potential to electric field (response function) that represented the pipeline/earth relation at each site.

The electrical answer of a pipeline to the geomagnetic induction was modelled by using a modified Ohm's Law for the pipeline current PI according to [2].

$$
(\mathrm{PI})(\mathrm{mA})=\left[-0.56 \times 10^{-3}(\mathrm{PV})\right]
$$

Figure 3 and Figure 4 show the PV and the PI values for June 12-13, 2005 as obtained by Equations (3) and (4), respectively.

\section{Conclusions}

The localized Earth potentials can produce significant effects on power systems and pipelines. The corrosion is increased by the electric currents that spread though the ground during magnetic storms and substorms; the difference in potential with the ground (PV) can become positive by several volts, resulting in electron leakage. For the studied case, during a moderate geomagnetic storm we observed that:

1) The PV values were always negatives, but during some periods, they were greater than $-850 \mathrm{mV}$, as was shown in Figure 3;

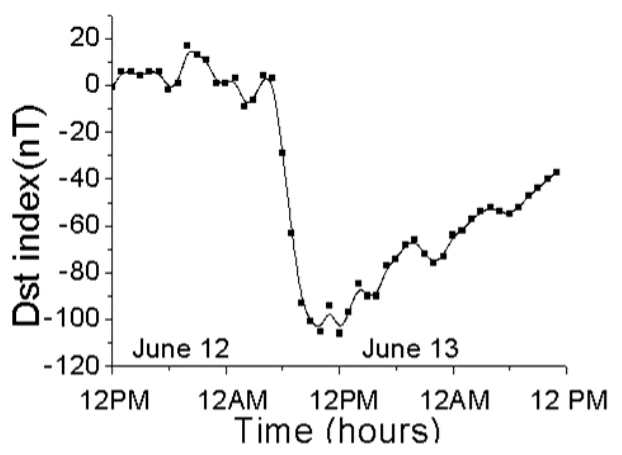

Figure 2. Temporal evolution of Dst index for June 12-13, 2005. This plot shows the typical evolution of the Dst index during a storm period. 


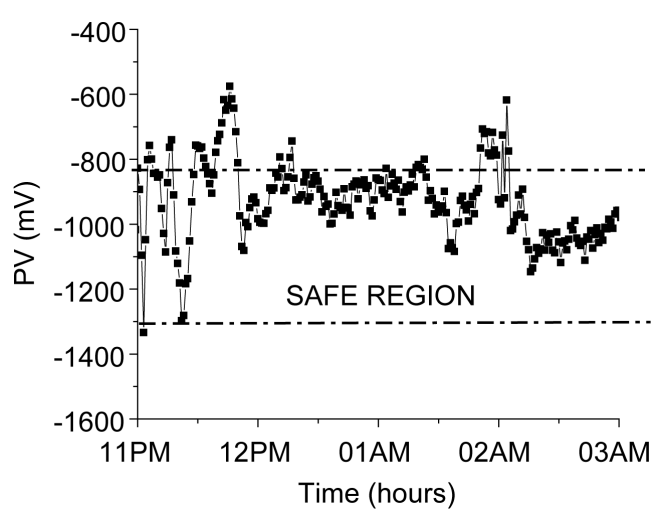

Figure 3. Pipe-to-soil potential difference (PV) on a pipeline in Canada, recorded at the same time of the magnetic storm period. During this period PV went outside the safe region indicating the possibility to increase the corrosion.

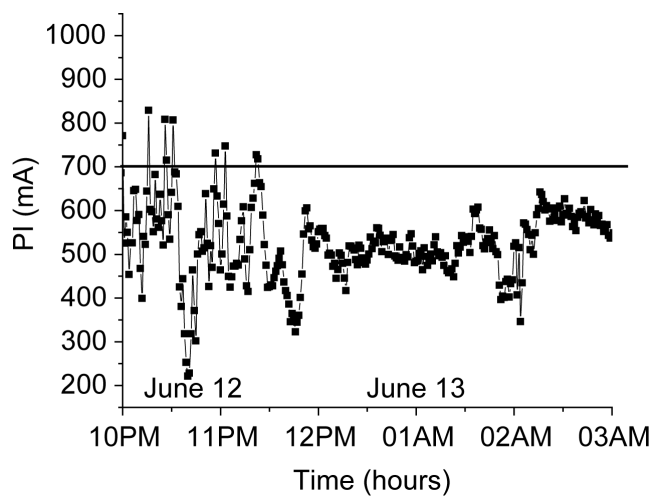

Figure 4. Induced currents (PI) for June 12-13, 2005. During some periods, the maximum PI values were up to $700 \mathrm{~mA}$.

2) During some periods, the maximum PI values were up to $700 \mathrm{~mA}$ (Figure 4).

During some periods of this storm, PV values were outside of the safe region, and then the possibility of additional corrosion was increased.

\section{Acknowledgements}

The authors would like to thank the grant of UBACYT of the Universidad de Buenos Aires (PIP 20020120100270) and CONICET (PIP 11420090100258) of Argentina. The data were obtained from WDC C2, (Kyoto, Japan) and from the Geological Survey of Canada.

\section{References}

[1] Fernberg, P., Samson, C., Boteler, D., Trichtchenko, L. and Larocca, P. (2007) Earth Conductivity Structures and Their Effects on Geomagnetic Induction in Pipelines. Annales Geophysicae, 25, 207-218. http://dx.doi.org/10.5194/angeo-25-207-2007

[2] Campbell, W.H. (1978) Induction of Auroral Zone Electric Currents within the Alaska Pipeline. Pure and Applied Geophysics, 116, 1143-1173. http://dx.doi.org/10.1007/BF00874677

[3] Boteler, D.H. and Seager, W.H. (1998) Telluric Currents: A Meeting of Theory and Observations. Corrosion, 54, 751755. http://dx.doi.org/10.5006/1.3284894

[4] Pulkkinen, A., Viljanen, A., Pajunpaa, K. and Pirjola, R.J. (2001) Recordings and Occurrence of Geomagnetically Induced Currents in the Finish Natural Gas Pipeline Networks. Journal of Applied Geophysics, 48, 219-231. http://dx.doi.org/10.1016/S0926-9851(01)00108-2 
[5] Pirjola, R. (2002) Geomagnetically Induced Currents during Magnetic Storms. IEEE Transactions on Plasma Science, 28, 1867-1873.

[6] Trichtchenko, L. and Boteler, D.H. (2001) Specification of Geomagnetically Induced Electric Fields and Currents in Pipelines. Journal of Geophysical Research, 106, 21039-21048. http://dx.doi.org/10.1029/2000JA000207

[7] Trichtchenko, L. and Boteler, D.H. (2002) Modeling of Geomagnetic Induction in Pipelines. Annales Geophysicae, 20, 1063-1072. http://dx.doi.org/10.5194/angeo-20-1063-2002

[8] Trichtchenko, L., Boteler, D.H. and Larocca, P. (2004) Modeling the Effect of the Electromagnetic Environment on Pipelines. Geological Survey of Canada Open File No. 4826.

[9] Boteler, D.H. (2000) Geomagnetic Effects on the Pipe-to-Soil Potentials of a Continetal Pipeline. Advances in Space Research, 26, 15-20. http://dx.doi.org/10.1016/S0273-1177(99)01020-0

[10] Peabody, A.W. (2000) Control of Pipeline Corrosion. National Association of Corrosion Engineers (NACE International), Houston, 1-360.

[11] Perreault, P. and Akasofu, S.I. (1978) A Study Geomagnetic Storms. Geophysical Journal International, 54, $547-573$. http://dx.doi.org/10.1111/j.1365-246X.1978.tb05494.x

[12] Sugiura, M. and Poros,D.J. (1971) Hourly Values of Equatorial Dst for the Years 1957 to 1970 Hourly Values of Equatorial Dst for the Years 1957 to 1970. GSFC, Greenbelt, Maryland.

[13] Larocca, P.A. and Silbergleit, V.M. (2010) Períodos perturbados: Disipación de energía y corrientes geomagnéticas inducidas. Geoacta, 35, 17-24. 